\title{
Analysis of the interaction between human kidney anion exchanger 1 and kanadaptin using yeast two-hybrid systems
}

\author{
Phonphimon Wongthida ${ }^{1,2}$, Varaporn Akkarapatumwong ${ }^{1}$, Thawornchai Limjindaporn ${ }^{3}$, \\ Saranya Kittanakom ${ }^{2}$, Thitima Keskanokwong ${ }^{1}$, Lily Eurwilaichitr ${ }^{4}$ and Pa-thai Yenchitsomanus ${ }^{2}$ \\ ${ }^{1}$ Mahidol University, Institute of Molecular Biology and Genetics, Salaya Campus, Nakhon Pathom, \\ Thailand. \\ ${ }^{2}$ Mahidol University, Siriraj Hospital, Faculty of Medicine, Department of Research and Development, \\ Division of Medical Molecular Biology and BIOTEC - Medical Biotechnology Unit, Bangkok, Thailand. \\ ${ }^{3}$ Mahidol University, Siriraj Hospital, Faculty of Medicine, Department of Anatomy, Bangkok, Thailand. \\ ${ }^{4}$ BIOTEC Central Research Unit, Klongluang, Pathumthani, Thailand.
}

\begin{abstract}
Kidney anion exchanger adaptor protein (Kanadaptin) is a protein which interacts with the cytoplasmic N-terminal domain of kidney anion exchanger 1 (KAE1) and was first detected in mice using the yeast two-hybrid system and was also found to co-localize with kAE1 in rabbit $\alpha$-intercalated cells. Impaired trafficking of human kAE1 can result in the kidney disease-distal renal tubular acidosis (dRTA), and defective interaction between human kAE1 and kanadaptin may cause this trafficking impairment and be the basis for dRTA pathogenesis. However, it is unknown whether $\mathrm{kAE} 1$ can really interact with kanadaptin in humans. We have thus investigated the interaction between human KAE1 and human kanadaptin by using both Gal4 and LexA yeast two-hybrid systems. It was found that co-expression of Gal4DBD fused to the cytoplasmic N-terminal domain of kAE1 and Gal4AD fused to kanadaptin could not activate the transcription of the ADE2, HIS3 and lacZ reporters in the Gal4 system. A similar result was obtained for the interaction between B42AD fused to the cytoplasmic N-terminal domain of kAE1 and LexA fused to kanadaptin in activation of lacZ transcription in the LexA system. The absence of interaction between the fusion proteins in both yeast two-hybrid systems raises the possibility that kAE1 may not interact with kanadaptin in human cells. Considerably different structures of both kAE1 and kanadaptin in mice and humans may lead to different binding properties of the proteins in these two species.
\end{abstract}

Key words: kidney anion exchanger 1, kanadaptin, yeast two-hybrid system.

Received: January 11, 2005; Accepted: August 1, 2005.

\section{Introduction}

Human anion exchanger 1 (AE1), an integral membrane protein with 911 amino acid residues (Drickamer et al., 1978; Jennings et al., 1989), consists of two isoforms, erythroid AE1 (eAE1 or band 3) and kidney AE1 (kAE1). Erythroid AE1 is the major integral protein of the erythrocyte plasma membrane where it is responsible for the dual roles of the electroneutral exchange of $\mathrm{Cl}^{-} / \mathrm{HCO}_{3}{ }^{-}$across the plasma membrane and cytoskeletal anchorage (Showe et al., 1987). Kidney AE1 is located on the basolateral membrane of acid-secreting $\alpha$-intercalated cells of the distal tubule and collecting duct of the nephron and is identical to

Send correspondence to Pa-thai Yenchitsomanus. Mahidol University, Siriraj Hospital, Faculty of Medicine, Department of Research and Development, Division of Medical Molecular Biology, Bangkok, 10700 Thailand. E-mail:grpye@mahidol.ac.th.
eAE1 except that transcription of kAE1 occurs from an alternative initiation site within intron 3 leading to a protein with a truncated N-terminus. Mouse kAE1 lacks 79 $\mathrm{N}$-terminal amino acid residues and human kAE1 65, because of which kAE1 no longer binds to ankyrin, protein 4.1, or glycolytic enzymes (Drenckhahn and Merte, 1987; Brosius et al., 1989; Kollert-Jons et al., 1993; Zhang et al., 2000).

Mutations in the human $A E 1$ gene may lead to the kidney disease known as distal renal tubular acidosis (dRTA) (Bruce et al., 1997; Rysava et al., 1997; Jarolim et al., 1998; Karet et al., 1998; Tanphaichitr et al., 1998; Vasuvattakul S. et al., 1999; Bruce et al., 2000; Yenchitsomanus et al., 2002) characterized by defective urinary acidification in the distal nephron, which is unable to lower urine $\mathrm{pH}$ to less than 5.5 in the presence of metabolic acidosis, frequently accompanied by hypokalemia, 
nephrocalcinosis and metabolic bone disease (Morris and Sebastian, 1983). Unlike wild-type kAE1, the mutant proteins exhibited intracellular retention when they were studied in non-polarized cells (Quilty et al., 2002a; Quilty et al., 2002b; Toye et al., 2002; Kittanakom et al., 2004a). However, in polarized cells, dRTA mutations cause either intracellular retention (Toye et al., 2004) or apical mistargeting of the proteins (Devonald et al., 2003; Toye et al., 2004; Rungroj et al., 2004). The correct trafficking of kAE1 may require both $\mathrm{N}$ - and C-termini (Devonald et al., 2003; Toye et al., 2004). Tyrosine-based sorting signals locating at these regions may interact with adaptor-protein complexes (Bonifacino and Dell'Angelica, 1999; Mostov et al., 2000). However, studies using the proximal renal tubular cell line LLC-PK1 lacking the $\mu 1 \mathrm{~B}$ subunit have indicated that the $\mu 1 \mathrm{~B}$ subunit of the AP1B adapter protein may not be involved in $\mathrm{kAE} 1$ trafficking to the basolateral membrane (Devonald et al., 2003; Toye et al., 2004) and that other adaptor proteins may be involved. In red cells, glycophorin acts as a chaperone in eAE1 trafficking (Young et al., 2000) but in kidney cells there is as yet no information as to the protein involved in $\mathrm{kAE} 1$ trafficking or the checkpoint for normal kAE1 trafficking nor is there any indication as to how kAE1 trafficking fails. Thus, to understand kAE1 transport, targeting, and regulation, it will be necessary to identify the proteins that bind to kAE1.

Kidney anion exchanger adaptor protein (kanadaptin) was first isolated from mice using the Gal4 yeast twohybrid system. A cytoplasmic N-terminal kAE1 domain was used as a bait to screen its interactor in mouse kidney cDNA library and kanadaptin was identified (Chen et al., 1998). Mouse kanadaptin consists of 507 amino acid residues and has a multi-domain structure with three distinctive putative nuclear localizing sequences (NLSs). Northern blot analysis demonstrated that mouse kanadaptin was widely expressed in lung, liver, brain, testis, heart, skeletal muscle and kidney tissues and that it was co-localized with kAE1 in intracellular vesicles but not in the basolateral membrane of rabbit $\alpha$-intercalated cells (Chen et al., 1998). This suggests that kanadaptin might play a role in the targeting of kAE1-containing vesicles to basolateral membrane of $\alpha$-intercalated cells. However, immunofluorescence and subcellular fractionation studies have demonstrated that kanadaptin is localized within the nuclei of various epithelial and non-epithelial cultured cell types (Hubner et al., 2002) and immuno-staining revealed strong kanadaptin signals in association with the mitochondria of proximal and distal tubule cells, cerebella cortex cells, enterocytes, hepatocytes and pancreatic acinar cells (Hubner et al., 2003).

Human kanadaptin cDNA (AY028435) was cloned and characterized by our group. The human kanadaptin protein contains 796 amino acids, has 262 amino acids longer than mouse kanadaptin at its N-terminus and has the extra 28 amino acid residues (codons 708 to 735) inserted near the C-terminus (Figure 1). However, the role of kanadaptin in human cells has not yet been demonstrated but the evidence from mouse and rabbit cells indicate that human kanadaptin may have a similar function in the targeting of kAE1-containing vesicles to their final destination. Since it is known that kAE1 defect results in dRTA, the failure of interaction between kAE1 and kanadaptin may lead to impaired trafficking of kAE1 to the basolateral membrane of the $\alpha$-intercalated cells where it mediates $\mathrm{Cl}^{-} / \mathrm{HCO}_{3}{ }^{-}$exchange thereby producing dRTA.

The yeast two-hybrid system is a powerful genetic tool to rapidly select uncharacterized proteins specifically interacting with a target protein of interest from a suitable cDNA library or to determine whether two known proteins interact with one another (Finley, 1995). This technique takes advantage of the modular domain structure of eukaryotic transcription factor. Eukaryotic transcription activators have at least two distinct functional domains, the DNA-binding domain that directly binds to the specific DNA sequences and the activation domain that activates transcription (Fields and Song, 1989). To study proteinprotein interaction, protein $\mathrm{X}$ is first fused to the DNAbinding domain (DBD) and then protein $\mathrm{Y}$ is fused to activation domain $(\mathrm{AD})$, the interaction between proteins $\mathrm{X}$ and $\mathrm{Y}$ leading to the reconstitution of a functional transcription factor and activation of a reporter gene. The most commonly used yeast two-hybrid systems are the Gal4 system (Fields and Song, 1989) in which the Gal4 transcriptional activator involved in galactose metabolism is reconstituted and the LexA system (Gyuris et al., 1993) which uses the operator sequence and binding domain (BD) from the $E$. coli lexA repressor protein. The use of two different systems with the same protein as a bait sometimes produce different results because the different fusion proteins may affect protein folding and interfere with the protein-protein

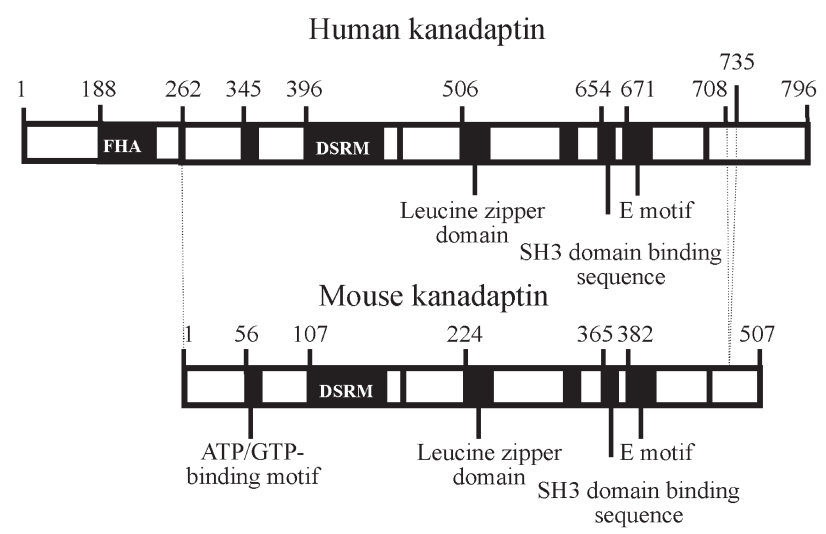

Figure 1 - Differences in structure between human and mouse kanadaptin. The upper picture shows human kanadaptin and the lower picture mouse kanadaptin. Human kanadaptin has 262 amino acids more than mouse kanadaptin at the N-terminal region containing forkhead-associated (FHA) domain and an extra 28 amino acid residues (positions 708 to 735 ) inserted near the C-terminal region which is not present in mouse kanadaptin. DSRM = double-stranded RNA-binding motif, E motif = glutamic acid motif and $\mathrm{SH} 3=$ Src homology domain 3. 
interaction (Criekinge and Beyaert, 1999). Some proteins may show interaction in the LexA system but not in the Gal4 system, e.g. the interaction between SopA and SopB of F plasmid (Kim and Shim, 1999).

In this study both the Gal4 and LexA yeast twohybrid systems were used to investigate the interaction between the cytoplasmic N-terminal domain of human kAE1 and human kanadaptin. In the Gal4 system, Gal4DBD was fused to kAE1 and Gal4AD to kanadaptin, while in the LexA system, B42AD was fused to kAE1 and LexA to kanadaptin. In both systems, the interactions were studied by mating and co-transformation procedures.

\section{Materials and Methods}

\section{Materials}

The yeast, Saccharomyces cerevisiae, strains AH109 (MATa, trp1-901, leu2-3, 112, ura3-52, his3-200, gal4A, gal80A, LYS2::GAL1 $1_{\mathrm{UAS}^{-}}$GAL1 $1_{\mathrm{TATA}^{-}}$HIS3, GAL2 ${ }_{\mathrm{UAS}^{-}}$ GAL2 $2_{\mathrm{TATA}}-A D E 2 \quad U R A 3: \because M E L 1_{\mathrm{UAS}}-M E L 1_{\mathrm{TATA}} \quad-l a c Z$ MEL1), and Y187 (MAT $\alpha$, ura3-52, his3-200, ade2-101,

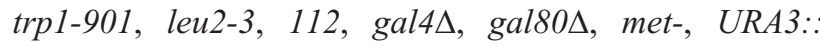
GAL1 $1_{\mathrm{UAS}}-G A L 1_{\mathrm{TATA}^{-}}$lacZ MEL1), the plasmid pGBKT7, pGADT-7, monoclonal anti-LexA, monoclonal antiGal4DBD and polyclonal anti-HA antibodies were purchased from Clontech (Franklin Lakes, USA). Yeast ( $S$. cerevisiae) strains RFY231 (MAT $\alpha$ ura3-1 his3 trp $1 \Delta:$ : hisG 3LexAop-LEU2::leu2), and RFY206 (MATa

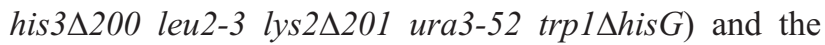
plasmid pNLex and pJZ4 were kindly donated by Associate Professor Russell L. Finley Jr., Wayne State University, School of Medicine, Michigan. The propagation host for the recombinant DNA plasmid was Escherichia coli (E.

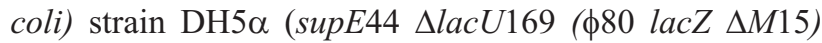
hsdR 17 recA1 endA1 gyrA96 thi-1 relA1) from a stock culture maintained in our laboratory. Affinity-purification used ProBond ${ }^{\mathrm{TM}} \mathrm{Ni}^{2+}$ beads from Invitrogen (Calsbad, USA). X-gal (5-bromo-4-chloro-3-indolyl- $\beta$-D-galactoside) was purchased from ROTH (Karlsruhe, Germany) and O-nitrophenyl- $\beta$-D-galactopyranoside (ONPG) was purchased from Sigma Chemical Co. (St. Louis, USA).

\section{Cloning of human kanadaptin cDNA}

Human kanadaptin cDNA was amplified and isolated by the polymerase chain reaction (PCR) from cDNAs prepared from human kidney mRNA. Total RNA was prepared from autopsied kidney tissue homogenate using TRIzol $^{\circledR}$ reagent (Life Technologies, Gaithersburg, MD, USA). The full-length human cDNAs were synthesized using the oligo(dT) $12-18$ primer and SUPERSCRIPT ${ }^{\mathrm{TM}}$ Preamplification System for First Strand cDNA Synthesis (Life Technologies). Human kanadaptin primers for two-step (nested) PCRs were designed from human expressed sequence tags (ESTs) searched by using the mouse kanadap- tin mRNA sequence. The PCR was performed in a GeneAmp PCR system 9700 (PE Applied Biosystems, Foster City, CA, USA) for 30 cycles, each cycle consisting of $94^{\circ} \mathrm{C}$ for $30 \mathrm{~s}, 55^{\circ} \mathrm{C}$ for $30 \mathrm{~s}$ and $72{ }^{\circ} \mathrm{C}$ for $3 \mathrm{~min}(10 \mathrm{~min}$ for the final cycle). The primary PCR product was then used as a template for nested PCR under the same conditions. The PCR product was detected by gel electrophoresis and purified using the QIAquick Gel Extraction Kit (QIAGEN, Germany) for sequencing analysis using the ABI PRISM Dye Terminal Cycle Sequencing Ready Reaction Kit (ABI, USA) and ABI-PRISM 310 Genetic Analyzer (ABI, USA). The human kanadaptin sequence was deposited in GenBank (AY028435). The isolated human kanadaptin cDNA was cloned into the XhoI and EcoRI sites of prokaryotic (pTrcHisA) vector and transformed into $E$. coli cells strain DH5 $\alpha$. The recombinant plasmids were screened by plasmid mini-preparation and restriction endonuclease digestion. Human kanadaptin protein was expressed in $E$. coli and purified for polyclonal antibody production.

\section{Production of mouse polyclonal anti-human kanadaptin antibody}

Mouse polyclonal anti-sera directed against human kanadaptin was generated using 6xHis-kanadaptin fusion protein as an immunogen. The recombinant human kanadaptin protein was expressed as a fusion protein with a 6xHis tag at the amino-terminus in E. coli using the pTrcHisA vector. Expression of 6xHis-kanadaptin fusion protein was induced by adding $0.25 \mathrm{mM}$ isopropyl-1-thio$\beta$-D-galactopyranoside (IPTG) at $20^{\circ} \mathrm{C}$ for $6 \mathrm{~h}$. The bacterial cells were sonicated in the presence of protease inhibitor, centrifuged to generate soluble and particulate fractions. To verify protein expression in each fraction, samples were fractionated by SDS-PAGE and Western blotting was carried out using an anti-6xHis antibody. Affinity-purification with ProBond ${ }^{\mathrm{TM}} \mathrm{Ni}^{2+}$ beads was used to purify 6xHis-kanadaptin eluted with $100 \mathrm{mM}$ imidazole. To generate polyclonal antibody against human kanadaptin, we immunized mice with affinity-purified 6xHiskanadaptin. In the first immunization, 6xHis-kanadaptin (20-60 $\mu \mathrm{g}$ protein) was combined with equal volume of complete Freund's adjuvant and then subcutaneously injected into mice. After 2 weeks, anti-kanadaptin antibody was raised and the antibody titer was checked by dot-blot enzyme immunoassay. Mice were boosted for two weeks with 6xHis-kanadaptin without any adjuvant after which they were sacrificed and the heart blood centrifuged to collect serum, which was then stored at $-20^{\circ} \mathrm{C}$. Specificity of antibody was confirmed by Western blot analysis.

\section{Yeast strains and growth condition}

For the Gal4 yeast two-hybrid experiments, we used S. cerevisiae strains AH109 and Y187 while for the LexA system we used $S$. cerevisiae strains RFY231 and RFY206. The yeasts were grown at $30^{\circ} \mathrm{C}$ in yeast extract potato dex- 
trose medium (YPD) or in a synthetic defined (SD) minimal medium supplemented with amino acids and glucose.

\section{Construction of recombinant plasmids}

A recombinant plasmid (pADkAE1) containing the cytoplasmic N-terminal domain of human kAE1 cDNA (encoding amino acids 66-403 of AE1, Figure 2) was constructed by amplifying kAE1 cDNA available in our laboratory and digesting the purified PCR product with EcoRI and $X h o I$, followed by ligation into the EcoRI and XhoI sites of plasmid pJZ4 (expressing the nuclear localizing signal, B42 activation domain and the HA-epitope tag). Plasmid pGalkAE1 containing the cytoplasmic N-terminal domain of kAE1 cDNA fused to Gal4BD was constructed by amplifying the kAE1 sequence (encoding amino acids 65-403) and inserting it into the pGBKT7 plasmid. Plasmid pLexKd containing full-length human kanadaptin cDNA $(2.4 \mathrm{~kb})$ in $\mathrm{pNLex}$ (expressing the fusion protein, nuclear localizing signal and LexA protein) was constructed by amplifying kanadaptin cDNA and digesting the purified PCR product with EcoRI and SalI. After digestion the purified fragment was ligated with EcoRI/SalI-digested pNLex. Plasmid pGalKd was constructed by digesting pLexKd with EcoRI and SalI. The kanadaptin cDNA fragment was sub-cloned into EcoRI/XhoI-digested pGADT4 (Gal4 binding domain fused to SV40). All recombinant plasmids were verified by DNA sequencing.

\section{Western blot analysis}

Protein expression in yeasts was examined by Western blot analysis. The yeast cells were lysed by resuspending in 1 volume of $2 \mathrm{x}$ breaking buffer $(50 \mathrm{mM}$ Tris- $\mathrm{HCl} \mathrm{pH}$ $8.0,0.1 \% \mathrm{v} / \mathrm{v}$ Triton $^{\circledR} \mathrm{X}-100$ and $\left.0.05 \% \mathrm{v} / \mathrm{v} \mathrm{SDS}\right)$ in the presence of $1 \mathrm{mM}$ PMSF purchased from Sigma Chemical Co. (St. Louis, USA) to prevent protease activities. The protein samples were separated in SDS-PAGE gels and transferred to nitrocellulose membranes. In the Gal4 system, the expression of the Gal4DBD-kAE1 fusion protein

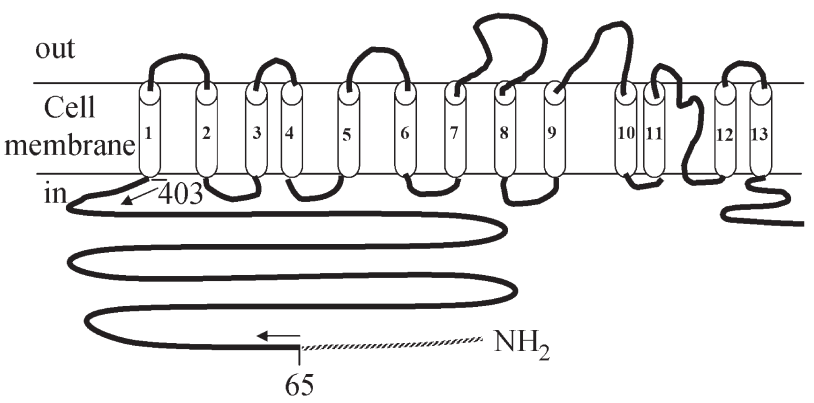

Figure 2 - Schematic representation of human erythroid and kidney anion exchanger 1 (AE1) protein structure. Human eAE1 is composed of three domains, the cytoplasmic N-terminal domain, the transmembrane domain and the cytoplasmic C-terminal domain. Human kAE1 lacks 65 amino acids present at the N-terminus of eAE1. The region of 66-403 amino acids of the cytoplasmic N-terminal domain of AE1 was fused to either Ga14DBD or B42AD to study their interactions with human kanadaptin in the Gal4 and LexA yeast two-hybrid systems, respectively. was detected using monoclonal anti-Gal4DBD as primary antibody and HRP-conjugated anti-mouse IgG as secondary antibody. The expression of the Gal4AD-kanadaptin fusion protein was detected using polyclonal anti-human kanadaptin as primary antibody and HRP-conjugated anti-mouse IgG as secondary antibody.

In the LexA system, the expression of the B42ADkAE1 fusion protein was detected using polyclonal antiHA-tag as primary antibody and HRP-conjugated anti-rabbit IgG as secondary antibody. The LexA-kanadaptin fusion protein was detected using either polyclonal anti-human kanadaptin or monoclonal anti-LexA as primary antibody followed by adding HRP-conjugated anti-mouse IgG.

The binding of secondary antibody to primary antibody was subsequently detected using the Sigma ECL plus Western Blotting Detection System by incubating for $5 \mathrm{~min}$. To detect chemiluminescence the membrane was exposed to X-ray film in a cassette for $30 \mathrm{~min}$ and the film developed normally.

Analysis of protein-protein interaction using the Gal4 yeast two-hybrid system

To study kAE1 and kanadaptin interaction, yeast strain AH109 containing pkAE1 was mated with yeast strain Y187 containing pGalKd or the plasmids pGalKd and pGalkAE1 were co-transformed into yeast strain AH109. Transformants were selected on glu/trp-leu- dropout plates. The interaction between the two proteins was determined by activation of three reporter genes, HIS3, ADE2 and $l a c Z$ on glu/trp leu ${ }^{-}$his $^{-}$ade $^{-}$dropout plates and by assaying the activity of $\beta$-galactosidase in the transformant yeasts.

Analysis of protein-protein interaction using the LexA yeast two-hybrid system

The interaction between kAE1 and kanadaptin was also examined by mating yeast strain RFY231 containing pkAE1M0 with yeast strain RFY206 containing pBDKdM0 and pSH18-34 (the lacZ reporter) or by cotransformation of the plasmids pADkAE1 and pLexKd into yeast strain RFY231 containing pSH18-34. Transformants were selected on glu/ura'his ${ }^{-} \operatorname{trp}^{-}$dropout plates. The interaction between the two proteins was determined by activation of two reporter genes, LEU2 and lacZ on gal/raf/

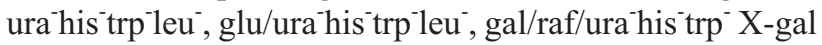
and glu/ura his $\operatorname{trp}^{-} \mathrm{X}$-gal plates . The activity of $\beta$-galactosidase in the transformant yeasts containing both recombinant plasmids was also determined.

\section{Assay of $\beta$-galactosidase activity}

To measure $\beta$-galactosidase activity, a single yeast colony was grown in $10 \mathrm{~mL}$ glucose dropout medium suitable for each yeast transformant. The cultures were incubated at $30{ }^{\circ} \mathrm{C}$ with shaking $(\sim 250 \mathrm{rpm})$ for $16 \mathrm{~h}$ and then transferred to $40 \mathrm{~mL}$ of the same dropout medium and incu- 
bated at $30{ }^{\circ} \mathrm{C}$ with shaking $(\sim 250 \mathrm{rpm})$ until the culture reached an optical density (OD) of $\sim 0.7$ at $600 \mathrm{~nm}$. The cells were washed twice with $10 \mathrm{~mL}$ of sterile water to prevent nutrient carry-over from the glucose medium and then transferred to $50 \mathrm{~mL}$ of galactose/raffinose dropout medium and incubated at $30^{\circ} \mathrm{C}$ with shaking $(\sim 250 \mathrm{rpm})$ for 2 days to induce expression of the protein. The reaction tube was set up with a known volume (v) of cell suspension diluted to $1 \mathrm{~mL}$ with $\mathrm{Z}$ buffer $\left(60 \mathrm{mM} \mathrm{Na} \mathrm{HPO}_{4} \cdot 7 \mathrm{H}_{2} \mathrm{O}\right.$, $40 \mathrm{mM} \mathrm{NaH}{ }_{2} \mathrm{PO}_{4} \cdot \mathrm{H}_{2} \mathrm{O}, 10 \mathrm{mM} \mathrm{KCl}, 1 \mathrm{mM} \mathrm{MgSO}{ }_{4} \cdot 7 \mathrm{H}_{2} \mathrm{O}$, and $50 \mathrm{mM} 2$-mercaptoethanol). A drop of $0.1 \%$ of SDS and two drops of chloroform were added to each reaction mixture, which was then heated at $30^{\circ} \mathrm{C}$ in a water bath for $15 \mathrm{~min}$ before adding $0.2 \mathrm{~mL}$ of $4 \mathrm{mg} \mathrm{mL}^{-1}$ ONPG. Betagalactosidase activity was detected with $o$-nitrophenol at $420 \mathrm{~nm}$ (Miller, 1972).

\section{Results}

\section{Expression of the fusion proteins in yeast}

In the Gal4 system, the expression of Gal4DBD$\mathrm{kAE} 1$ and Gal4AD-kanadaptin fusion proteins in yeasts were tested by Western blot analysis using polyclonal antiGal4DBD and anti-human kanadaptin as primary antibodies, respectively. As expected, the Gal4DBD-kAE1 fusion protein was $60 \mathrm{kDa}$ (Figure 3A). The Gal4AD-kanadaptin fusion protein was expressed and detected by anti-human kanadaptin (Figure 3B) and was found to have a molecular weight of $150 \mathrm{kDa}$ which was greater than the expected $119 \mathrm{kDa}$, possibly due to post-translational modification such as glycosylation of the fusion protein in the yeast.

In the LexA system, the B42AD-kAE1 fusion protein was found to be $62 \mathrm{kDa}$ as expected (Figure 3C) after detection using polyclonal anti-HA. The LexA-kanadaptin fusion protein was found to be expressed after detection by either polyclonal anti-human kanadaptin (Figure 3D) or monoclonal anti-LexA as primary antibody (data not shown). The fusion protein had a molecular weight of $150 \mathrm{kDa}$, which was greater than the expected $110 \mathrm{kD}$, possibly due to the same reasons as suggested above for the Gal4AD-kanadaptin fusion product.

\section{Interaction between human kanadaptin and kAE1 in the Gal4 system}

To make sure that both kAE1 and kanadaptin fusion did not activate the reporter gene by themselves, we tested for auto-activation and found that neither Gal4DBD-kAE1 nor Gal4AD-kanadaptin auto-activated the reporter genes (data not shown). The interaction was then examined by mating yeast cells expressing Gal4DBD-kAE1 with yeast cells expressing Gal4AD-kanadaptin. These yeast cells could not grow on dropout plates lacking histidine and adenine (Figure 4A), indicating that the Gal4DBD-kAE1 and Gal4AD-kanadaptin fusion proteins could not interact to activate HIS3 and ADE2 genes in the yeast cells. Further-
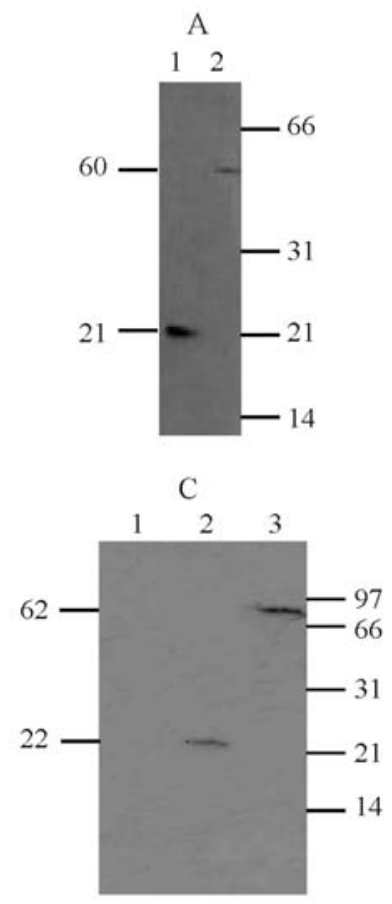
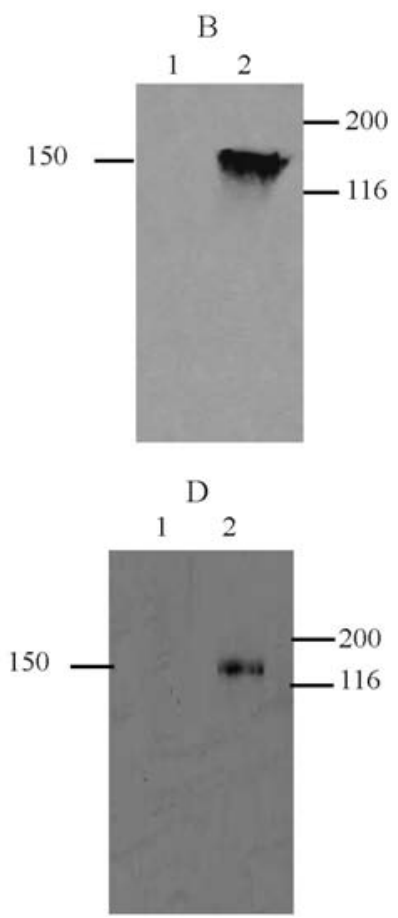

Figure 3 - Western blot analysis of fusion protein expression in yeasts. (A) Gal4DBD-kAE1 expression was detected with mouse monoclonal antibody against Gal4DBD. Lane 1 is the crude extract of AH109 containing pGBKT7 and lane 2 the crude extract of AH109 containing pGalkAE1. The Gal4DBD and Gal4DBD-kAE1 fusion proteins are expressed at $21 \mathrm{kDa}$ (lane 1) and $60 \mathrm{kDa}$ (lane 2), respectively. (B) Gal4AD-kanadaptin expression was detected with mouse polyclonal anti-human kanadaptin antibody. Lane 1 is a crude extract of Y187 and lane 2 is a crude extract of Y187 transformed with pGalKd. The size of the Gal4AD-kanadaptin fusion protein is about $150 \mathrm{kDa}$. (C) The expression of B42AD-kAE1 was detected with rabbit polyclonal anti-HA antibody. Lane 1 is a crude extract of RFY231, lane 2 is a crude extract of RFY231 containing pJZ4 and lane 3 is a crude extract of RFY231 containing pADkAE1. The B42AD-kAE1 fusion protein is $62 \mathrm{kDa}$ in size. (D) The expression of LexA-kanadaptin was detected with mouse polyclonal anti-human kanadaptin antibody. Lane 1 is a crude extract of RFY206-lacZ and lane 2 is a crude extract of RFY206-lacZ transformed with pLexKd. The LexA-kanadaptin fusion protein is expressed at the size of about $150 \mathrm{kDa}$.

more, the result of the enzyme assay showed that $\beta$-galactosidase activity in the transformants expressing Gal4DBD-kAE1 and Gal4AD-kanadaptin fusion proteins were not significantly different from that of the negative controls (Figure 5A, Table 1). This finding indicates that the Gal4DBD-kAE1 and Gal4AD-kanadaptin fusion proteins expressed in yeast might not interact with one another and thereby not activating the $l a c Z$ reporter gene.

The interaction between the Gal4DBD-kAE1 and Gal4AD-kanadaptin fusion proteins was also investigated by co-transformation in yeast cells. The fusion proteins showed no auto-activation of the two reporters HIS3 and $A D E 2$. Yeast cells expressing both the Gal4DBD-kAE1 and Gal4AD-kanadaptin fusion proteins could not grow on dropout plates lacking histidine and adenine (data not shown), indicating that no interaction between these two fusion proteins occurred. 
A

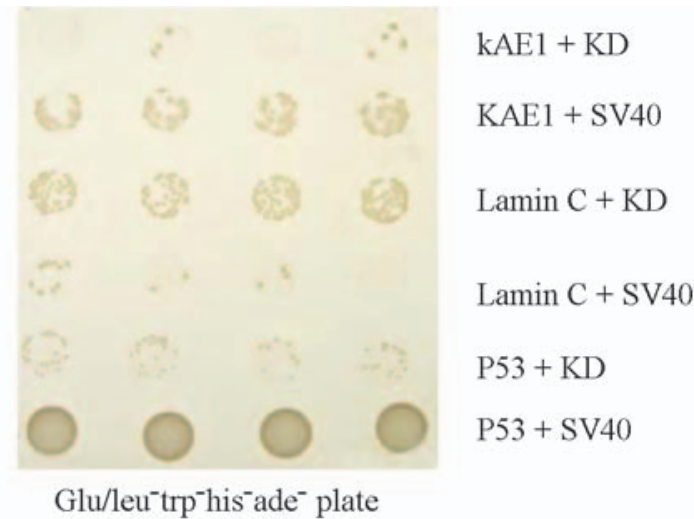

B

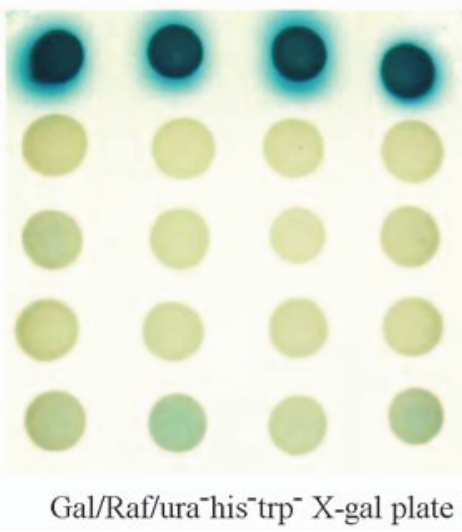

DmCdc2 + DmCdi2

$\mathrm{BD}+\mathrm{AD}$

$\mathrm{BD}+\mathrm{kAE} 1$

$\mathrm{KD}+\mathrm{AD}$

$\mathrm{KD}+\mathrm{kAE} 1$

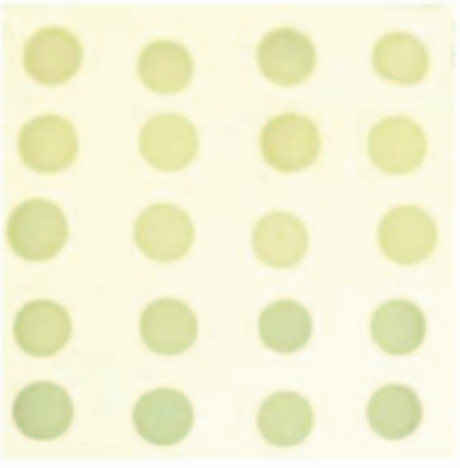

Glu/ura`histrp- X-gal plate

Figure 4 - Analyses of fusion protein interactions after mating two yeast transformants. (A) Gal4 yeast two-hybrid. Yeast cells AH109 containing pGalkAE1 were mated with yeast cells Y187 containing pGalKd. Mating transformants expressing p53 and SV40 large T antigen were used as positive controls and mating transformants expressing lamin C and SV40 large T antigen were used as negative controls. Each spot represents an individual diploid after mating. Yeast transformants grew at $30^{\circ} \mathrm{C}$ for 4 days on glu/leu ${ }^{-}$trp $^{-}$his $^{-}$ade $^{-}$dropout plates. (B) LexA yeast two-hybrid. Yeast cells RFY231 containing pADkAE1 were mated with yeast cells RFY206-lacZ containing pLexKd. Yeast cells expressing DmCdc2 and DmCdi2 were used as positive controls and yeast cells expressing $\mathrm{BD}$ and $\mathrm{AD}$ were used as negative controls. Each spot represents an individual diploid after mating. Yeast transformants grew at $30^{\circ} \mathrm{C}$ for 4 days on the dropout plates as indicated.

\section{Interaction between human kanadaptin and KAE1 in the LexA system}

The B42AD-kAE1 and LexA-kanadaptin fusion proteins were tested for auto-activation of the two reporter genes $L E U 2$ and lacZ before performing the mating assay. The result showed that B42AD-kAE1 did not activate the lac $Z$ reporter gene but LexA-kanadaptin weakly activated transcription of this gene (data not shown). To test the interaction by mating assay, yeast cells expressing B42AD-kAE1 fusion protein were mated with yeast cells expressing LexA-kanadaptin fusion protein. The result showed that these yeast cells gave faint blue colonies on the plates containing X-gal in both gal/raf and glu dropout media (Figure 4B). This might have been the result of weak auto-activation of the reporter gene by LexA-kanadaptin. The activity of $\beta$-galactosidase for the transformants expressing B42AD-kAE1 and LexA-kanadaptin fusion proteins were not significantly different from that of the clones expressing LexA and B42AD-kAE1, and LexA-kanadaptin and B42AD, respectively (Figure 5B, Table 1)
Table 1 - Gal4 and LexA yeast two-hybrid $\beta$-galactosidase activity assays. Two separate colonies from each clone were assayed and each colony was independently assayed in triplicate $(\mathrm{N}=6)$.

\begin{tabular}{|c|c|c|}
\hline System & $\begin{array}{c}\text { Yeast } \\
\text { transformants }\end{array}$ & $\begin{array}{c}\text { Units of } \beta \text {-galactosidase } \\
\text { activity } \pm \mathrm{SEM}^{1}\end{array}$ \\
\hline \multirow{6}{*}{$\begin{array}{l}\text { Gal4 yeast } \\
\text { two-hybrid }\end{array}$} & $\mathrm{p} 53+\mathrm{SV} 40$ & $109.96 \pm 9.51$ \\
\hline & $\mathrm{p} 53+\mathrm{KD}$ & $0.14 \pm 0.00$ \\
\hline & Lamin C + SV40 & $0.23 \pm 0.01$ \\
\hline & Lamin $C+K D$ & $0.25 \pm 0.02$ \\
\hline & $\mathrm{kAE} 1+\mathrm{SV} 40$ & $0.69 \pm 0.02$ \\
\hline & $\mathrm{kAE} 1+\mathrm{KD}$ & $0.68 \pm 0.01$ \\
\hline \multirow{5}{*}{$\begin{array}{l}\text { LexA yeast } \\
\text { two-hybrid }\end{array}$} & $\mathrm{DmCdc} 2+\mathrm{DmCdi} 2$ & $79.18 \pm 4.90$ \\
\hline & $\mathrm{LexA}+\mathrm{B} 42 \mathrm{AD}$ & $0.30 \pm 0.04$ \\
\hline & LexA + kAE1 & $0.41 \pm 0.04$ \\
\hline & $\mathrm{B} 42 \mathrm{AD}+\mathrm{KD}$ & $2.45 \pm 0.14$ \\
\hline & $\mathrm{kAE} 1+\mathrm{KD}$ & $2.10 \pm 0.05$ \\
\hline
\end{tabular}

${ }^{1}$ Standard error of the mean. 


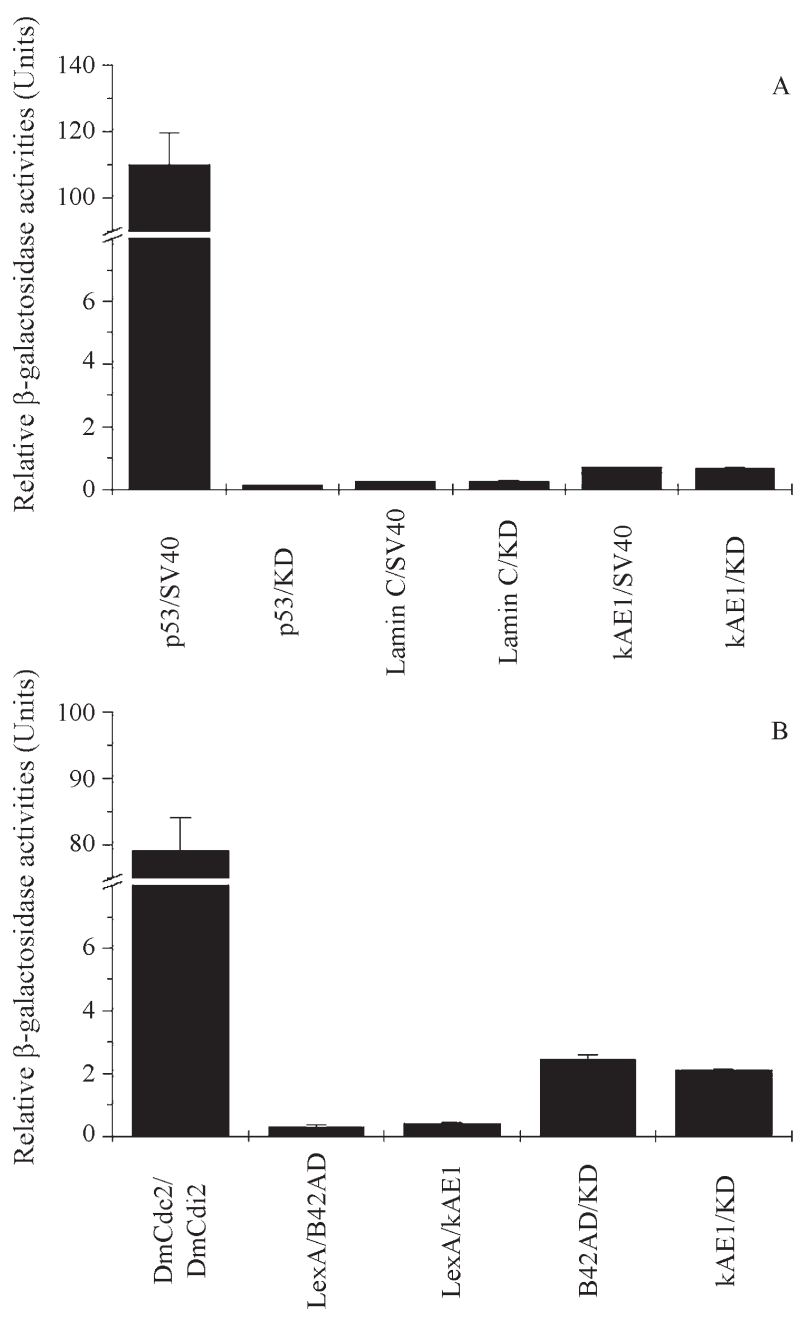

Figure 5 - Beta-galactosidase activity for determination of fusion protein interactions in yeast-two hybrid studies. The bar graphs illustrate the relative $\beta$-galactosidase activities (units) in cell lysates from mating yeasttransformants expressing the different pairs of proteins or fusion proteins as indicated. Two separate colonies from each clone were assayed and each colony was independently assayed in triplicate $(\mathrm{N}=6)$. There was no obvious difference in activity from six independent experiments so no error bar could be shown in the experiments that showed minimal or absent activities. (A) The $\beta$-galactosidase assay in the Gal4 yeast-two hybrid system. Transformants expressing p53 and SV40 large T antigen were used as positive controls and transformants expressing lamin C and SV40 large T antigen as negative controls. Transformants expressing different combinations of fusion proteins were also used as additional controls. (B) The $\beta$ galactosidase assay in the LexA yeast two-hybrid system. Transformants expressing DmCdc2 and DmCdi2 were used as positive controls and transformants expressing $\mathrm{BD}$ and $\mathrm{AD}$ as negative controls. Transformants expressing different combinations of fusion proteins were also used as additional controls.

In the co-transformation assay, B42AD-kAE1 and LexA-kanadaptin fusion proteins were also tested for autoactivation with the two reporters LEU2 and lacZ before performing the interaction. The result showed that transformants containing B42AD-kAE1 showed no autoactivation of the $L E U 2$ and lacZ reporter genes while the transformants containing LexA-kanadaptin could grow on media lacking leucine and gave faint blue colonies on X-gal plates as compared to a negative control (data not shown). Yeast cells expressing B42AD-kAE1 and LexA-kanadaptin grew on dropout plates lacking leucine and gave faint blue colonies on the X-gal plates. However, the $\beta$ galactosidase assay showed that the enzyme activity of the transformants expressing B42AD-kAE1 and LexA-kanadaptin were not significantly different from those of negative controls (data not shown).

\section{Discussion}

In this study, we used the Gal4 and LexA yeast two-hybrid systems to investigate whether the cytoplasmic N-terminal domain of human kAE1 can physically interact with human kanadaptin. By using these yeast two-hybrid systems in conjunction with mating and co-transformation procedures, we found that the cytoplasmic N-terminal domain of human kAE1 could not interact with human kanadaptin because none of the reporter genes were activated. In a different study by our group using cultured human embryonic kidney (HEK293) cells, we have also observed that human kAE1 and kanadaptin co-expressed in these cells were located at different sites when detected by immunofluorescence staining (Kittanakom S. et al., 2004b). kAE1 was present at the plasma membrane and cytoplasm whereas kanadaptin was localized predominantly in the nucleus. In addition, no interaction between kAE1 (or eAE1) and kanadaptin expressed in HEK293 cells could be demonstrated either by co-immunoprecipitation or $6 \mathrm{xHis-}$ tagged co-purification methods. Thus, in contrast to data from mouse kanadaptin, human kanadaptin may not interact with kAE1 in human kidney cells.

Different kAE1 and kanadaptin structures occur in humans and mice and these may affect their ability to bind to other proteins. Comparison between human and mouse cytoplasmic N-terminal domains of kAE1 showed about $25 \%$ difference in their amino acid sequences. As compared to mouse kanadaptin, human kanadaptin contains an additional $262 \mathrm{~N}$-terminal amino acids and a 28 amino acid insertion near the C-terminus. Since most of the human kanadaptin appears to be highly homologous to murine kanadaptin, it is possible that the additional 262 amino acids found at the N-terminus of human kanadaptin that are absent from mouse kanadaptin may occlude or interfere with binding to the human kAE1 N-terminus. The detailed analysis of amino acids 1 to 262 of human kanadaptin using the simple modular architecture research tool (SMART, Schultz et al., 1998; Schultz et al., 2000) showed that this region contains a forkhead-associated (FHA) domain between amino acid residues 188 and 249 (Figure 1). The FHA domain is a multifunctional phosphopeptide-binding module that has been found in a wide variety of proteins from both prokaryotes and eukaryotes (Hofmann and. Bucher, 1995; Sun et al., 1998; Durocher et al., 1999; Li et al., 1999; Liao et al., 1999; Hammet et al., 2000) and was 
first identified in a group of forkhead transcription factors (Hofmann and Bucher, 1995) and has since been identified in many signaling proteins, including protein kinases, protein phosphatases, proteases, kinesins and zinc finger proteins in both yeasts and animals (Schultz et al., 2000). The Chk2-like cell cycle checkpoint protein kinases play crucial roles in cellular damage and replication blocks and are characterized by the presence of FHA domain (Matsuoka et al., 1998). The existence of FHA domain suggests that human kanadaptin may be involved in other, different, cellular processes.

Kanadaptin is widely expressed in many mouse tissues such as kidney, lung, liver, brain, testis, heart, and skeletal muscle (Chen et al., 1998) but not in the $\alpha$-intercalated cells of rat and rabbit kidney (Hubner et al., 2003), while kAE1 only expresses in kidney $\alpha$-intercalated cells. Kanadaptin is a multi-domain structure containing three nuclear localizing sequences (NLS) involved in translocation of this protein into the nucleus of mammalian cells (Hubner et al., 2003), indicating that this protein may have a signaling role in the nucleus. Furthermore, immunofluorescence staining has revealed strong kanadaptin signals in association with the mitochondria of several cell types such as proximal and distal tubule cells, cerebellar cortex cells, enterocytes, hepatocytes and pancreatic acinar cells (Hubner et al., 2003). From these findings and the results of our yeast two-hybrid and eukaryotic expression studies, it is therefore unlikely that human kanadaptin is involved in targeting kAE1 to the plasma membrane and is also unlikely that defects in kanadaptin and its interaction with $\mathrm{kAE} 1$ results in distal renal tubular acidosis (dRTA).

\section{Acknowledgments}

We thank Assoc. Prof. Russell L. Finley Jr., Wayne State University, School of Medicine, Michigan, USA, for kindly providing the plasmid vectors and yeast cells and for valuable suggestions, and Assoc. Prof. Pattama Ekpo, Department of Immunology, Faculty of Medicine Siriraj Hospital, for helping in kanadaptin antibody production.. This work was financially supported by the Development and Promotion of Science and Technology Talent Project (DPST) (to P.W.), and the National Center for Genetic Engineering and Biotechnology (BIOTEC), Thailand (to P.Y.). We also thank Prof. Sakol Panyim, the former Director of Institute of Molecular Biology and Genetics, and Dr. Prida Malasit, the Director of BIOTEC-Medical Biotechnology Unit and the Division of Medical Molecular Biology, Department of Research and Development, Faculty of Medicine Siriraj Hospital, for their continuous supports. The two supporters are recipients of Senior Research Scholar Award of Thailand Research Fund (TRF).

\section{References}

Bonifacino JS and Dell'Angelica EC (1999) Molecular bases for the recognition of tyrosine-based sorting signals. J Cell Biol 145:923-926.

Brosius FC, Alper SL, Garcia AM and Lodish HF (1989) The major kidney band 3 gene transcript predicts an amino-terminal truncated band 3 polypeptide. J Biol Chem 264:7784-7787.

Bruce LJ, Cope DL, Jones GK, Schofield AE, Burley M, Povey S, Unwin RJ, Wrong O and Tanner MJ (1997) Familial distal renal tubular acidosis is associated with mutations in the red cell anion exchanger (Band 3, AE1) gene. J Clin Invest 100:1693-1707.

Bruce LJ, Wrong O, Toye AM, Young MT, Ogle G, Ismail Z, Sinha AK, McMaster P, Hwaihwanje I, Nash GB, Hart S, Lavu E, Palmer R, Othman A, Unwin RJ and Tanner MJ (2000) Band 3 mutations, renal tubular acidosis and SouthEast Asian ovalocytosis in Malaysia and Papua New Guinea: Loss of up to $95 \%$ band 3 transport in red cells. Biochem J 350:41-51.

Chen J, Vijayakumar S, Li X and Al-Awqati Q (1998) Kanadaptin is a protein that interacts with the kidney but not the erythroid form of band 3. J Biol Chem 273:038-1043.

Criekinge WV and Beyaert R (1999) Yeast two-hybrid: State of art. Biological procedures online 2:1-38.

Devonald MA, Smith AN, Poon JP, Ihrke G and Karet FE (2003) Non-polarized targeting of AE1 causes autosomal dominant distal renal tubular acidosis. Nat Genet 33:125-127.

Drenckhahn D and Merte C (1987) Restriction of the human kidney band 3-like anion exchanger to specialized sbdomains of the basolateral plasma membrane of intercalated cell. Eur J Cell Biol 45:107-115.

Drickamer LK (1978) Orientation of the Band 3 polypepide from human erythrocyte membrane: Identification of $\mathrm{NH}_{2}$-terminal sequence and site of carbohydrate attachment. J Biol Chem 253:7242-7248.

Durocher D, Henckel J, Fersht AR and Jackson SP (1999) The FHA domain is a modular phosphopeptide recognition motif. Mol. Cell. 4:387-394.

Fields S and Song O (1989) A novel genetic system to detect protein-protein interactions. Nature 340:245-246.

Finley RL and Brent R (1995) Interaction trap cloning with yeast. In: DNA Cloning. Oxford University Press, Oxford, pp 169-203.

Gyuris J, Golemis EA, Chertov H and Brent R (1993) Cdi, a human G1 and $\mathrm{S}$ phase protein phosphatase that associates with Cdk2. Cell 75:791-803.

Hammet A, Pike BL, Mitchelhill KI, Teh T, Kobe B, House C.M, Kemp BE and Heierhorst J (2000) FHA domain boundaries of the Dun1p and RAD53p cell cycle checkpoint kinases. FEBS Lett. 471:141-146.

Hofmann K and Bucher P (1995) The FHA domain: A putative nuclear signalling domain found in protein kinases and transcription factors. Trends Biochem Sci. 20:347-349.

Hubner S, Bahr C, Gossmann H, Efthymiadis A and Drenckhahn D (2003) Mitochondrial and nuclear localization of kanadaptin. Eur J Cell Biol 82:240-252.

Hubner S, Jans DA, Xiao CY, John AP and Drenckhahn D (2002) Signal- and importin-dependent nuclear targeting of the kidney anion exchanger 1-binding protein kanadaptin. Biochem J 361:287-296. 
Jarolim P, Shayakul C, Prabakaran D, Jiang L, Stuart-Tilley A, Rubin HL, Simova S, Zavadil J, Herrin JT, Brouillette J, Somers MJ, Seemanova E, Brugnara C, Guay-Woodford LM and Alper SL (1998) Autosomal dominant distal renal tubular acidosis is associated in three families with heterozygosity for the $\mathrm{R} 589 \mathrm{H}$ mutation in the $\mathrm{AE} 1$ (band 3) $\mathrm{Cl}^{-} / \mathrm{HCO}_{3}{ }^{-}$exchanger. J Biol Chem 273:6380-6388.

Jennings ML (1989) Structure and function of the red cell anion transport protein. Annu Rev Biophys Chem 18:397-430.

Karet FE, Gainza FJ, Gyory AZ, Unwin RJ, Wrong O, Tanner MJ, Nayir A, Alpay H, Santos F, Hulton SA, Bakkaloglu A, Ozen S, Cunningham MJ, di Pietro A, Walker WG and Lifton RP (1998) Mutations in the chloride-bicarbonate exchanger gene AE1 cause autosomal dominant but not autosomal recessive distal renal tubular acidosis. Proc Natl Acad Sci USA 95:6337-6342.

Kim SK and Shim J (1999) Interaction between F plasmid partition proteins SopA and SopB. Biochem Biophys Res Commun 293:113-117.

Kittanakom S, Cordat E, Akkarapatumwong V, Yenchitsomanus $P$ and Reithmeier RA (2004a) Trafficking defects of a novel autosomal recessive distal renal tubular acidosis mutant (S773P) of the human kidney anion exchanger (kAE1). J Biol Chem. 279:40960-40971.

Kittanakom S, Keskanokwong T, Akkarapatumwong V, Yenchitsomanus P and Reithmeier RA (2004b) Human kanadaptin and kidney anion exchanger 1 (kAE1) do not interact in transfected HEK 293 cells. Mol Membr Biol 21:395-402.

Kollert-Jons A, Wagner S, Hubner S, Appelhans H and Drenckhahn D (1993) Anion exchanger 1 in human kidney and oncocytoma differs from erythroid $\mathrm{AE} 1$ in its $\mathrm{NH} 2$ terminus. Am J Physiol Renal Physiol 265:F813-821.

Li J, Smith GP and Walker JC (1999) Kinase interaction domain of kinase-associated protein phosphatase, a phosphoprotein-binding domain. Proc. Nat. Acad. Sci. USA 96:7821-7826.

Liao H, Byeon IJ and Tsai MD (1999) Structure and function of a new phosphopeptide-binding domain containing the FHA2 of Rad53. J. Mol. Biol. 294:1041-1049.

Matsuoka S, Huang M and Elledge SJ (1998) Linkage of ATM to cell cycle regulation by the Chk2 protein kinase. Science 282:1893-1897.

Miller JH (1972) Experiments in Molecular Genetics. Cold Spring Harbor Laboratory Press, Cold Spring Harbor, pp 352-355

Morris Jr RC, and Sebastian A (1983) Renal tubular acidosis and Fanconi syndrome. In: The Metabolic Basis of Inherited Disease. 5th, ed. McGraw-Hill, New York, pp 1808-1843.

Mostov KE, Verges M and Altschuler Y (2000) Membrane traffic in polarized epithelial cells. Curr Opin Cell Biol 12:483490.

Quilty JA, Cordat E and Reithmeier RA (2002a) Impaired trafficking of human kidney anion exchanger (kAE1) caused by hetero-oligomer formation with a truncated mutant associated with distal renal tubular acidosis. Biochem J 368:895903.

Quilty JA, Li J and Reithmeier RA (2002b) Impaired trafficking of distal renal tubular acidosis mutants of the human kidney anion exchanger kAE1. Am J Physiol Renal Physiol 282:F810-820.
Rungroj N, Devonald MA, Cuthbert AW, Reimann F, Akkarapatumwong V, Yenchitsomanus PT, Bennett WM and Karet FE (2004) A novel missense mutation in AE1 causing autosomal dominant distal renal tubular acidosis retains normal transport function but is mistargeted in polarized epithelial cells. J Biol Chem 279:13833-13838.

Rysava R, Tesar V, Jirsa Jr M, Brabec V and Jarolim P (1997) Incomplete distal renal tubular acidosis coinherited with a mutation in the band 3 (AE1) gene. Nephrol Dial Transplant 12:1869-1873.

Schultz J, Copley RR, Doerks T, Ponting CP and Bork P (2000) SMART: A web-based tool for the study of genetically mobile domains. Nucleic Acids Res 28:231-234.

Schultz J, Copley RR, Doerks T, Ponting CP and Bork P (2000) SMART: A web-based tool for the study of genetically mobile domains. Nucl. Acids Res. 28:231-234.

Schultz J, Milpetz F and Hofmann K (1998) SMART, a simple modular architechiture research tool: Identification of signaling domains. Proc Natl Acad Sci 95:5857-5864.

Showe LC, Ballantine M and Huebner K (1987) Localization of the gene for the erythroid anion exchange protein, band 3 (EMPB3), to human chromosome 17. Genomics 1:71-76.

Sun Z, Hsiao J, Fay DS and Stern DF (1998) RAD53 FHA domain associated with phosphorylated Rad9 in the DNA damage checkpoint. Science 281:272-274.

Tanphaichitr VS, Sumboonnanonda A, Ideguchi H, Shayakul C, Brugnara C, Takao M, Veerakul G and Alper SL (1998) Novel AE1 mutations in recessive distal renal tubular acidosis. Loss-of-function is rescued by glycophorin A. J Clin Invest 102:2173-2179.

Toye AM, Bruce LJ, Unwin RJ, Wrong O and Tanner MJ (2002) Band 3 Walton, a C-terminal deletion associated with distal renal tubular acidosis, is expressed in the red cell membrane but retained internally in kidney cells. Blood 99:342-347.

Toye AM, Banting G and Tanner MJ (2004) Regions of human kidney anion exchanger $1(\mathrm{kAE} 1)$ required for basolateral targeting of kAE1 in polarised kidney cells: Mis-targeting explains dominant renal tubular acidosis (dRTA). J Cell Sci 117:1399-1410.

Vasuvattakul S, Yenchitsomanus P, Vachuanichsanong P, Thuwajit P. Kaitwatcharachai., Laosombat V, Malasit P, Wilairat P and Nimmannit S (1999) Autosomal recessive distal renal tubular acidosis associated with southeast asian ovalocytosis. Kidney Int 56:1674-1682.

Yenchitsomanus P, Vasuvattakul S, Kirdpon S, Wasanawatana S, Susaengrat W, Sreethiphayawan S, Chuawatana D, Mingkum S, Sawasdee N, Thuwajit P, Wilairat P, Malasit P and Nimmannit S (2002) Autosomal recessive distal renal tubular acidosis caused by G701D mutation of anion exchanger 1 gene. Am J Kidney Dis 40:21-29.

Young MT, Beckmann R, Toye AM and Tanner MJ (2000) Red-cell glycophorin A-band 3 interactions associated with the movement of band 3 to the cell surface. Biochem $\mathrm{J}$ 350:53-60.

Zhang D, Kiyatkin A, Bolin JT and Low PS (2000) Crytallographic structure and functional interpretatio of cytoplasmic domain of erytrocyte membrane band 3. Blood 96:29252933.

Associate Editor: Emmanuel Dias Neto 